and 1,639 trees and 188 poles and at different seasons of the year, have shown that farmers and other users of wood-lot trees can increase the durability of fence posts and so forth with little expense and labour. Stepping and capping are simple operations, and the circular furnishes full information with useful photographs on how to proceed.

\section{INTERNATIONAL VETERINARY AND LIVESTOCK SECRETARIAT FOR THE FAR EAST}

\begin{abstract}
A CONFERENCE of Far Eastern Member Govern. ments convened by the United Nations Relief and Rehabilitation Administration was held in Sydney, Australia, during December 1945. A wide range of problems was discussed, and as a result an UNRRA (South-West Pacific Area) International Veterinary and Livestock Secretariat for the Far East was set up.

The following were represented at the Conference : the British and American Far Eastern Commands, the United States of America, Australia, New Zealand, India, Netherlands Indies, China, and the Philippines. The executive officer of the Secretariat is Major William Granger, c/o UNRRA, 52 William Street, Sydney, New South Wales.
\end{abstract}

At the conference it was emphasized that the rehabilitation of war-ravaged countries must include the restoration of their livestock industries, livestock being essential for the supply of food and also for clothing, transport and agriculture. In certain of the far eastern countries the livestock population has been greatly reduced as a result of the War. It is essential to safeguard them against the ravages of epizootic disease, and in the earlier post-war period there are special dangers in this respect, the conditions which lead to the introduction and spread of certain diseases being operative on account of the prevailing circumstances. It will be necessary for certain countries to import livestock and, unless stringent precautions are taken to ensure that epizootic diseases are not introduced by such livestock and that the animals are protected against such disease after their arrival, the consequences might be serious. Furthermore, steps must be taken to ensure that malnutrition and inefficient breeding practices do not take a toll on animal health.

It is the intention that the member countries of the International Veterinary and Livestock Secretariat will supply check lists of communicable diseases of livestock in their territories, with indications as to their prevalence and distribution. New occurrences of scheduled diseases will be notified by cable. The Secretariat will prepare monthly statistical bulletins of this information and will work in liaison with the Office International des Epizooties in Paris. Information will be pooled and distributed concerning the nature of veterinary organisations in force in the several countries and of the education and training of the staffs. There will be a general information service concerning aspects of livestock industries. Systems of health certification for animal traffic will be arranged, and it is anticipated that this will be extended to certification as to genital soundness in the case of breeding stock.

Information relating to biological products will be provided, attention being given to methods of manu- facture and standardization and control. Details will be provided about methods of inspection and certification of meat and meat products and of animal products such as dairy produce, eggs, hides and skins and hair and wool intended for export, member countries being encouraged, where this is not already done, to place inspection and control of such products under veterinary supervision.

Exchanges will be facilitated of administrative, research and other veterinary and livestock workers between member countries, and postgraduate educational facilities will be provided. Where necessary, in emergency, arrangements will be made for veterinary staffs to be sent on loan from one member country to another.

The livestock requirements of the several territories will be assessed and their resources of potential exports, also their resources in personnel, equipment and fodder needed for the use and care of imported livestock in recipient countries.

It is anticipated that ultimately the Secretariat may develop into a Far Eastern Pacific Branch of a comprehensive world organisation under the control of the United Nations Organisation, along with the Office International des Epizooties. Countries not members of the United Nations Relief and Rehabilitation Administration (South-West Pacific Area) that have territories bordering on the Pacific Area will be invited to co-operate in, and support the work of, the Secretariat.

Special attention will be paid to the presence in various countries of animals particularly adapted to tropical conditions or having resistance to disease, with the aim of utilizing them in the course of building up the livestock populations.

Full details of the Conference and of the circumstances which led to its convocation are given in a report issued from the office of the Secretariat*. In addition, there is matter which takes up more than half the extent of the report, concerning League of Nations publications of 1928-35 and of a Commonwealth of Australia, Department of Health Service publication of 1935 , containing information regarding subjects that fall within the scope of this new organisation.

* United Nations Relief and Rehabilitation Administration, Southwest Paciflc Area. . Proceedings of Conference of Veterinary Represent- $^{\text {atives of Far Eastern Member Governments of UNRRA and of the }}$ Military Commands, held at 52 William Street, Sydney, Australia, on 14th, 15th and 17th December 1945. Pp. 82. (52 William Street, Sydney)

\section{FORTHCOMING EVENTS}

\section{(Meeting marked with an asterisk * is open to the public)}

\section{Tuesday, June 18}

ROYAL ANTHROPOLOGIOAL INSTITUTE (joint meeting with the INTERNATIONAL AFRICAN INSTITUTE, at 21 Bedford Square, London. Cyrenaica".

Wednesday, June 19

GEOLOGYCAI SOCTETY OF LONDON (at Burlington House, Piccadilly. London, W.1), at 5 p.m.- - Scientiflc Papers.

ChaLILenger Society (at the Linnean Society, Burlington House, Piccadilly, London, W.1), at 5.45 p.m.- Dr. S. M. Marshall and Dr. A. P. Orr: "Agar from British Seaweeds".

BRITISH PSYCHO-ANALYTICAI SOcIETY (at the Royal Society of Medicine, 1 Wimpole Street, London, W.1), at 8 p.m.-Prof. E. D. Adrian:" "The Physical and the Mental Sources of Behaviour" (First Annual Ernest Jones Lecture).

\section{Thursday, June 20}

London Mathematroal SocizTY (at the Royal Astronomical Society, Burlington House, Piccadilly, London, W.1), at 3 p.m.Mr. T. W. Chaundy : "The Arithmetic Minima of Positive Quadratic Forms". 